\title{
Family functioning and perceived support from nurses during cancer treatment among Danish and Australian patients and their families
}

\begin{abstract}
Aims and Objectives: This study aims to compare family functioning and perceptions of support from nurses among Danish and Australian adult oncology patients and family members.

Background: Family can have a strong influence on the health of individuals, providing support in a health crisis such as cancer. However, family functioning and supportive care from nurses may vary across cultures and settings.

Design and Methods: A descriptive, cross sectional comparative design with patients and family members from Denmark and Australia. Participants were asked to fill in translated versions of the Iceland-Expressive Family Functioning Questionnaire (ICE-EFFQ), and Iceland-Expressive Family Perceived Support Questionnaire (ICE-FPSQ).
\end{abstract}

Results: In total 232 participants were recruited. The Danish cohort consisted of 56 patients and 54 family members. The Australian cohort consisted of 83 patients and 39 family members. Mean age was 59 years. No significant differences were found between Danish and Australian families. However, compared to patients, family members reported significantly lower overall family functioning, expressive emotions, and communication, as well as less emotional support from nurses.

Conclusions: Family functioning was comparable between Denmark and Australia. Family members reported less emotional support than patients. Nurses need to consider the patient and the 
family as a unit with complex needs that require monitoring and attention during oncology treatment.

Implications for Practice: Families supporting a member with cancer have significant and often unmet needs. Assessment, information-sharing, and health education needs to include the family. Supportive care information may be shared between Denmark and Australia and inspire the development of common guidelines for optimal family nursing practice.

\section{Abstract words: 256}

Summary box: What does this paper contribute to the wider global clinical community?

- Family members supporting a patient undergoing cancer treatment report diminished family functioning, emotional wellbeing, and communication.

- Family members perceive that their emotional support needs are neglected by nurses.

- Similarities in patient and family experiences across countries support the feasibility of developing shared international guidelines to inform family nursing in the oncology context.

Keywords: Family; Support; Nursing; Family nursing; Cancer nursing. 


\section{Family functioning and perceived support from nurses during cancer treatment among Danish and Australian patients and their families}

\section{Introduction}

Cancer, like other chronic illnesses, is a family affair. When a family member becomes sick, the patient and their family are affected (Benzein et al. 2008, Wright \& Leahey 2013). Family members are often the primary caregivers for cancer patients and the most important resource to help patients cope with disease and illness. High level evidence from systematic reviews and meta-analyses confirm the stressful nature of a cancer diagnosis for patients and families (Northouse et al. 2012). Stress was related to the need for family to adjust and adapt to changes associated with the patient's disease process and treatment, as well as to their role as carers and support persons. However, family members may not always openly express their needs during this time (Northouse et al. 2012). Our study therefore explores perceptions of patients and family members in regards to family functioning and support from nurses during oncology treatment.

\section{Background}

Families supporting a member with cancer often have complex needs which may go unnoticed by health professionals (Kim et al. 2010, Northouse et al. 2012). Nurses may fail to understand the complex needs of family members, as nursing care predominantly focuses on the patient (Coyne et al. 2016). In a Danish cross-sectional study with palliative cancer patients ( $\mathrm{n}=$ 1490), 35\% reported that health care staff showed insufficient interest in the well-being of their relatives (Ross et al. 2012). In Denmark and Australia adult nursing is dedicated to a patient centred approach, which may have an unintended consequence of positioning the family as an 'outsider' (Coyne 2013) or 'on the sideline' (Dieperink et al. 2013).

Research in this field is just beginning to better understand the needs of family, and to consider the family as a unit that includes both the patient and family members. In Denmark, there 
has been limited research on family nursing and the effects of specific interventions that aim to support families during the illness of a family member (Dieperink et al. 2016, Ostergaard \& Wagner 2014). Similarly, Australian researchers have just begun to build an understanding about the importance of 'family inclusive care' but evidence is emerging in areas such as paediatrics (Bloomer et al. 2015, Munns \& Shields 2013), critical care (Bloomer et al. 2013, Kean \& Mitchell 2014, Wong et al. 2015), aged care (Bauer et al. 2014), disability care (Rillotta et al. 2012) and oncology (Coyne 2013). However, much of this research reports on the lack of consistency in engaging and supporting families by health professionals.

A diagnosis of cancer presents not only personal challenges but also in the ways the family work together. Family functioning has been defined as the interactions between family members in regards to their communication, traditions, roles and boundaries, and sense of resilience (Coyne et al. 2012, Winek 2010). Most research regarding family functioning has been conducted by psychologists, most often in the paediatric cancer area, and with tools measuring dyadic coping or relationship functioning (Pritchett et al. 2011). There has been limited research on family functioning and perceptions of support from nurses in adult cancer research. There is also a lack of tools developed for use with different family members such as partners or elderly parents.

Although the family is often the main source of support when an adult is diagnosed with cancer, we know relatively little about the perspectives of adult patients and their family members as a family unit when receiving cancer treatment in hospital. Perceptions of supportive care needs may differ between patients and family members and also between cultural settings. Although Denmark and Australia may have comparable lifestyle and health care systems, there are differences in regards to generous family leave provisions in Denmark, a diverse multi-cultural and geographically distant population distribution in Australia, and possible differences in family nursing approaches between countries which could influence families’ perceptions of functioning 
and supportive care needs. Understanding family functioning in different countries and settings will provide important knowledge to inform family nursing interventions in the future. Furthermore, to inform the development of international care guidelines, we need to know if supportive care needs are comparable across countries.

\section{Aims}

This study aimed to compare self-reported family functioning and perceptions of support from nurses among Danish and Australian oncology patients and their family members.

\section{Conceptual Framework}

The underlying conceptual framework of this study was drawn from Family Systems Nursing (Bell 2009, Wright \& Leahey 1990). 'The family' is considered the unit of assessment and investigation, who interact and influence each other, particularly in response to a health adversity (Harris et al. 2010, Walsh 2006). This perspective enables nurse researchers to explore the patient and their family members as a group rather than focusing on the patient alone. Family Systems Nursing also considers key processes including family functioning, communication, connectedness and adaptation (Friedman et al. 2003, Walsh 2006). Family Systems Nursing informs an approach to clinical practice known as the Calgary Family Assessment and Intervention Models (Wright \& Leahey 2013). According to the Calgary Family Assessment and Intervention Models the family is conceived as a group of individuals who are bound by strong emotional ties, a sense of belonging, a commitment to being involved in one another's lives, and who call themselves "family”. From this perspective, a family member does not need to be related to the patient, but is accepted as such if the patient considers a person to be family. We adopted this approach as one of the inclusion criteria in our study. The use of these two models guided our exploration of key concepts and processes within the family such as communication, collaboration, family structure and family relationships from the perspectives of patients and family. 


\section{Methods}

\section{Design}

This international study was conducted in Denmark and Australia using an exploratory descriptive cross sectional comparative design.

\section{Participants}

Adult patients receiving cancer treatment, and their family members were recruited from an oncology unit at hospitals in Denmark and Australia. Inclusion criteria were patients involved in active cancer treatment as an admitted patient or an outpatient basis and their nominated family members. Exclusion criteria were patients and family members who could not understand sufficient Danish or English to complete the questionnaires.

\section{Measurements}

Demographic data were collected on all participants and included age, gender, family status, educational level, occupation, postcode, and ethnic origin. Participating patients were also asked for clinical data such as cancer type, treatment approaches, and treatment location.

\section{Iceland Expressive Family Functioning and Perceived Support Questionnaires}

The survey also included the Iceland Expressive Family Functioning Questionnaire (ICE-EFFQ) (Sveinbjarnardottir et al. 2012a), and the Iceland Family Perceived Support Questionnaire (ICEFPSQ) (Sveinbjarnardottir et al. 2012b). These questionnaires both reflect concepts inherent in the

Calgary Family Assessment and Intervention Models (Wright \& Leahey 2013). Furthermore, the ICE-EFFQ and ICE-FPSQ were developed and psychometrically tested in three different studies of families and patient members experiencing mental health difficulties (Sveinbjarnardottir et al. 2013), chronic disease (Halldórsdóttir \& Svavarsdóttir 2012), and general acute hospital admission (Kamban \& Svavarsdottir 2013, Sveinbjarnardottir et al. 2012a, b). The instruments must be 
considered as valid instruments to measure both patients and family member's perspectives of family functioning and perceived support from nurses.

ICE-EFFQ has 17-items that measure family functioning where one member has a chronic or acute illness (Sveinbjarnardottir et al. 2012a). It consists of four multidimensional subscales: expressive emotions (4 items), collaboration and problem solving (5 items), communication (4 items) and behaviour (4 items). A 5-point Likert-type response scale ranging from 1 (almost never) to 5 (all of the time) was used. Scores can range from 17 to a maximum of 85 . Higher scores reflect better family functioning, but there is no exact cut-off score to distinguish between optimal and less than optimal family functioning. ICE-EFFQ shows good internal consistency with a Cronbach's alpha coefficient of 0.91 (Sveinbjarnardottir et al. 2012a).

ICE-FPSQ has 14-items that measure perceived cognitive support (5 items) and emotional support from nurses (9 items) (Sveinbjarnardottir et al. 2012b). The instrument uses a Likert scale with a scoring range between 1 (almost never) to 5 (all of the time), and has good internal consistency with a Cronbach's alpha coefficient of 0.96 (Sveinbjarnardottir et al. 2012b). Scores range from 14 to 70 with higher scores reflecting perceptions of better support. However, there is no exact cut-off score to distinguish between sufficient or insufficient support from nurses. The questionnaire has been used in studies with adult psychiatric patients (Sveinbjarnardottir et al. 2013) and families of children with acute illness (Kamban \& Svavarsdottir 2013).

Both ICE questionnaires have been validated in English, and previously translated and validated among Danish adult patients diagnosed with general medical diseases or cancer showing good internal consistency; Cronbach’s alpha 0.93 for ICE-EFFQ and 0.94 for ICE-FPSQ (unpublished 
material). In the current study Cronbach’s alpha was 0.75 for ICE-EFFQ and 0.82 for ICE-FPSQ indicating good internal consistency.

\section{Data collection}

Data were collected from July until September 2014 in Australia and Denmark. Each patient and their respective family member were approached by the researchers (KD or EC), given information about the study, and opportunities to ask questions. If a person met the inclusion criteria and wished to participate they were asked to complete the questionnaires individually. In Denmark participants primarily preferred to complete the survey at the time in the outpatient clinic, whereas in Australia most participants preferred to complete the forms at home and return the questionnaire in a pre-paid envelope.

\section{Statistical analysis}

Data were checked for accuracy of entry across the two countries. To minimise data entry errors, the database followed a prescribed codebook (Schneider \& Deenan 2004). Quality control procedures were followed (King \& Lashley 2000). Questionnaires with missing data in a scale were excluded (2 for ICE-EFFQ; 9 for ICE-FPSQ). Data were summarised using descriptive analysis, including means, standard deviations (SD) and frequency distributions. Demographic details were checked to ensure family group data were consistent.

The analysis of the data was conducted with constant comparison of patient and family to identify differences and similarities. Scale and subscale scores were compared using independent t-tests. Data were checked for normal distributions. Wilcoxon's test was used when the data did not meet assumptions for normality. Continuous outcome measures were analysed with multivariate linear regression models on the summary scores of family functioning ICE-EFFQ and perceived support from nurses on the ICE-FPSQ to understand if country, age, gender, patients or family members, or 
family status affected the outcome measures. Data analyses were conducted using STATA; and a two-sided $p$ value $<.05$ was considered significant.

\section{Ethics}

The investigation conforms to the principles outlined in the Declaration of Helsinki (World Medical Association 2008). This study was approved by the Griffith University Human Research Ethics Committee and from the hospital in Australia [GU Ref No: NRS/50/12/HREC] and was registered by the Danish Data Protection Agency [J.nr. 2014-41-3136]. Participants were informed that confidentiality would be maintained, and written consent was implied by returning the questionnaire. The lead authors from each country have a deep understanding of the cultures and clinical practices in each country with a professional background in clinical oncology nursing, but neither was working in the participating oncology units.

\section{Results}

In total 232 participants were recruited during the period, with 110 from Denmark and 122 from Australia. The Danish cohort consisted of 56 patients and 54 family members. The Australian cohort consisted of 83 patients and 39 family members. The majority of family members were spouses and others were children, sisters, or brothers.

Only a few individuals refused to participate when invited but details of refusers were not collected. In both countries, refusal to participate related to fatigue or survey questions being too sensitive. The Danish cohort had more completed family questionnaires due to a higher return response rate of $91 \%$; whereas the response rate for Australian family participants was $46 \%$. This difference in response rate was due in large part to Australian participants preferring to complete the questionnaire at home but then failing to return the questionnaire package via free mail. The 
anonymous nature of the survey made it impossible to follow-up these participants with any reminders and so they were lost to the study.

Age range spanned 14-95 years, with a mean of 59 years (SD 12.8). The gender of participants was 53\% $(n=124)$ female and 47\% $(n=108)$ male. There were no significant differences for age or gender between the two countries. Detailed information about patients and family members is outlined in Table 1. Cancer diagnosis was similar across Denmark and Australia, but there were no Danish haematological patients. Most patients (59\%) had a combined treatment regime involving surgery, chemotherapy and radiotherapy. More Australian participants were being treated as inpatient than an oncology day patient compared with Danish participants $(\mathrm{p}<.001)$.

Table 1 Demographic and Clinical Characteristics of Participants from Australia and Denmark (n=232) 


\begin{tabular}{lll}
\hline Characteristics & $\begin{array}{l}\text { Australia } \\
\mathrm{n}=122\end{array}$ & $\begin{array}{l}\text { Denmark } \\
\mathrm{n}=110\end{array}$ \\
\hline Patients, $\mathbf{n}$ & 83 & 56 \\
Male, n (\%) & $44(53)$ & $24(43)$ \\
Female, n (\%) & $39(47)$ & $32(57)$ \\
Age, year, mean (SD) & $63(12)$ & $59(11)$ \\
\hline Family members, $\mathbf{n}$ & 39 & 54 \\
Male, n (\%) & $11(28)$ & $29(54)$ \\
Female, n (\%) & $28(72)$ & $25(46)$ \\
Age, mean (SD) & $56(15)$ & $56(14)$ \\
\hline Educational level, $\mathbf{n}$ & & $53(49)$ \\
$\quad$ (\%) & $81(66)$ & $14(13)$ \\
Secondary School & $22(18)$ & $35(32)$ \\
Diploma & $12(10)$ & $7(6)$ \\
University degree & $7(6)$ & \\
Post graduates & &
\end{tabular}

All Danish participants were Caucasian, as were the majority of Australian participants, but 4\% were Indigenous Australian, 1.6\% were Asian and 2.4\% were from other ethnic origins. Around half the sample (56\%) were married and had children older than 10 years. Fewer participants were married and had children younger than 10 years (6\%); married with no children (15\%); single (12\%); or reported other family arrangements (11\%).

Differences in educational background were noted between the two countries. In Australia a higher number of participants had diploma level education, whereas more Danish participants had a university degree. In regards to occupation, a higher percentage of Australians worked in trade 
positions or at home, and were self-employed or unemployed. In Denmark half the participants were in professional occupations.

Table 2 Comparison of family functioning (ICE-EFFQ) and perceived nursing support (ICE-FPSQ) during oncology treatment between Australian and Danish participants $(\mathbf{n}=\mathbf{2 3 2})$

\begin{tabular}{|c|c|c|c|c|c|}
\hline & $\begin{array}{r}\text { Australia } \\
n=1 \\
22\end{array}$ & & $\begin{array}{c}\text { Denmark } \\
\mathrm{n}=110\end{array}$ & & \\
\hline $\begin{array}{l}\text { Patient and family } \\
\text { members }\end{array}$ & Mean & SD & Mean & SD & $\begin{array}{l}P \\
\mathrm{v} \\
\mathrm{al} \\
\mathrm{u} \\
\mathrm{e}^{\mathrm{c}}\end{array}$ \\
\hline $\begin{array}{l}\text { ICE-EFFQ } \\
\text { Expressed emotions }\end{array}$ & 17.8 & 2.1 & 17.6 & 1.9 & .35 \\
\hline $\begin{array}{l}\text { Collaboration/Problem } \\
\text { solving }\end{array}$ & 21.7 & 3.2 & 21.0 & 3.2 & .08 \\
\hline Communication & 16.0 & 3.5 & 16.0 & 2.9 & .94 \\
\hline Behaviour & 16.8 & 3.3 & 16.8 & 2.5 & .94 \\
\hline \multicolumn{6}{|l|}{ 'E-EFFQ ${ }^{a}$} \\
\hline tal & 72.3 & 9.8 & 71.3 & 8.4 & .42 \\
\hline \multicolumn{6}{|l|}{ :E-FPSQ } \\
\hline gnitive support & 20.5 & 4.4 & 20.3 & 4.2 & .76 \\
\hline notional support & 28.1 & 12.4 & 25.6 & 10.3 & .10 \\
\hline \multicolumn{6}{|l|}{ :E-FPSQ ${ }^{\mathrm{b}}$} \\
\hline Total & 48.6 & 16.0 & 45.9 & 13.4 & .18 \\
\hline
\end{tabular}

E-EFFQ min score 17 point - max score 85 point

IE-FPSQ min score 14 point - max score 70 point

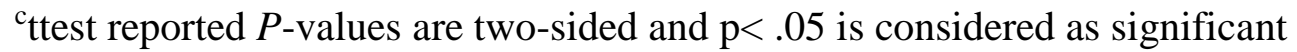

Abbreviations: SD, Standard Deviation. 
No significant differences were seen in family functioning scores (as measured by ICE-EFFQ) and perceptions of nursing support scores (as measured by ICE-FPSQ) between Danish and Australian participants (Table 2). Significant differences were identified between patients and family members from both countries, with family members scoring lower on overall family functioning, expressive emotions, and communication subscales, and in regards to emotional support from nurses (Table 3).

Table 3 Comparison of family functioning (ICE-EFFQ) and perceived nursing support (ICE-FPSQ) during oncology treatment between all patients and family members $(\mathbf{n}=232)$

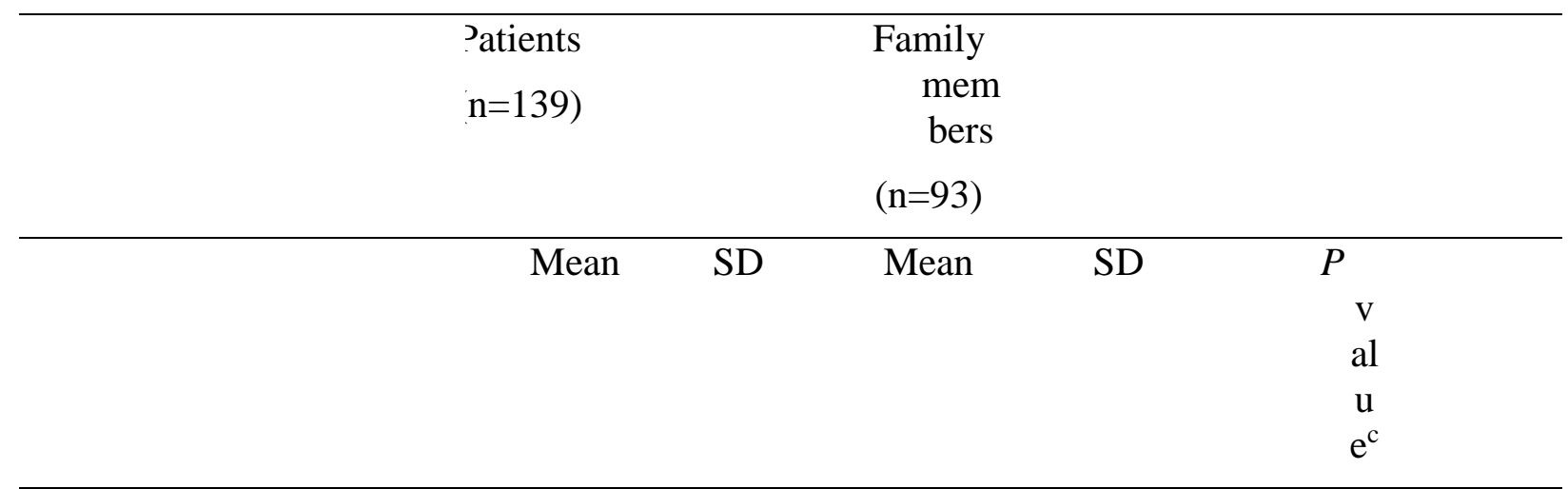

ICE-EFFQ, mean, SD 17.9 1.9 17.4

$2.1 \quad 7$

Express emotions

Collaboration/Problem solving 21.6 3.1 20.9

$3.4 \quad 7$

Communication 16.4

3.3

15.5

3.0 j

Behaviour 16.9 2.9

16.5

3.0 7

:E-EFFQ ${ }^{\mathrm{a}}$, mean, SD

ital

\section{:E-FPSQ}

gnitive support

20.8

28.4

4.0

19.8

4.7

9.3

7

notional support

\section{:E-FPSQ $^{\mathrm{b}}$}

Total

49.2

44.3

15.2 .02 
בE-EFFQ min score 17 point - max score 85 point

בE-FPSQ min score 14 point - max score 70 point

${ }^{c}$-test reported $P$-values are two-sided and $\mathrm{p}<.05$ is considered as significant

Abbreviations: SD, Standard Deviation.

The multiple linear regression showed no significant differences according to country, age or gender. Compared to patients, family members reported lower family functioning $(-2.5$ point $p=$ $.045,95 \% \mathrm{CI}=-5.0 ;-0.1)$; and lower perceptions of support from nurses $(-4.4$ point $p=.036,95 \%$ $\mathrm{CI}=-8.5 ;-0.3)$. Family members who were married and had children over ten years of age reported significantly better family functioning compared to married participants without children (4.4 point difference $p=.011,95 \% \mathrm{CI}=1.0 ; 7.7)$.

\section{Discussion}

This cross-sectional study compared family functioning and perceptions of supportive care from nurses by patients and families from Australia and Denmark. We identified no significant differences between the two country cohorts, but significant differences in the subgroup analyses between patients and family members were observed. Family members scored lower than patients on both family functioning and perceived support scales. The approximate five-point difference in perceived nursing support by patients and family members, as measured by the total ICE-FPSQ score, indicated a clinically important difference (Osoba et al. 1998). The main difference was in regard to families perceiving less emotional support. This difference could reflect the current 
orientation of nursing care in both countries around the patient. Our findings indicate that family members supporting the patient have unmet emotional needs that may adversely affect their coping.

Mean scores for family functioning obtained in our study were comparable with those of Icelandic families who completed the same questionnaires (Sveinbjarnardottir et al. 2012a). However, items relating to cognitive and emotional support from nurses scored higher in our study compared to those of Svavarsdottir and colleagues (2012a), which may be due to the different populations.

Family status was found to be a significant explanatory factor in our study. Married participants with children over ten years of age scored higher on the family functioning scale. This finding is similar to findings from another cross-sectional Danish study (n=1490), which found divorced people and people without children may be a more vulnerable group for impaired family functioning (Ross et al. 2012). However, Ross and colleagues also argued that much older people had higher levels of vulnerability. In our study, 23\% of participants were 70 years or older, although we did not find age to be a significant explanatory factor for lower total family functioning scores compared to younger participants. According to key elements in Family Systems Nursing, our findings confirm that family structure and relationships can have a positive impact on patient and family well-being during periods of adversity, but levels of coping may vary across different time spans for the family.

The similarities in overall family functioning between the two countries could be related to several factors. The health care systems in Denmark and Australia are comparable in many ways, with both utilizing a tax paid system to ensure equal and universal access to health care for patients. However, cancer treatment may place an additional economic burden on families for costs not covered by the health or social welfare system, such as transport and parking at the hospital, cost of medication after discharge, and cost of any complementary therapies. Those with private health 
insurance have a growing gap to pay between medical charges and rebates offered by insurers. Living conditions in Australia are more culturally diverse than in Denmark. Furthermore, the families’ supportive role may differ across countries according to gender roles, education level and working hours (Craig \& Mullan 2010, Rademakers et al. 2012). On average Australians work more hours and mothers are more likely to perform more child care responsibilities than women in Denmark (Craig \& Mullan 2010). In Denmark distances are less and extended family is closer, hence providing different forms of family support. Nonetheless this current study showed surprising similarity between the two countries in reported family functioning with a member receiving oncology care. This new knowledge leads to important possibilities of sharing nursing interventions and guidelines regarding nursing approaches for families during the cancer trajectory.

The findings of our study are in line with our conceptual model and other cancer research in highlighting that family members are in need of more systematic interventions that enable them to: 1) to carry out their caregiving role; and 2) engage in self-care at the same time (Northouse et al. 2010). Northouse et al (2010) concluded in a large systematic review that interventions targeting family members not only reduced caregiver burden, but also decreased adverse symptoms of stress in cancer patients. However, family-oriented interventions such as caregiver assessment and education about the disease are seldom implemented in practice (Northouse et al. 2012). The poor use of family interventions could be related to nursing care being predominantly focused on the patient, even though the importance of family nursing has been promoted for many years (Northouse et al. 2012, Yates 1999). Previous research has identified that nurses struggle to assess family needs and support families during oncology care (Coyne et al. 2016, Turner et al. 2007). Improving the quality of family assessment during oncology care may require continuing professional development for nurses and other health professionals, opportunities for skill 
development, and changes to workplace practices to afford nurses time to spend with family members.

Changing family nursing practices is also important in light of global population trends towards higher proportions of elderly in the health care system and people surviving cancer. The demands of these trends on health care systems in developed countries necessitate the need for nurses to optimize the abilities of family members to support the patient and each other.

The dilemmas facing family members during the cancer trajectory are complicated. For example, some researchers identified that family members may play down their own worries in order not to stress the patient (Dieperink et al. 2016, Northouse et al. 2012). Therefore, according to Family Systems Nursing, clinicians have an important role in identifying and optimising family functioning, providing education to them about possible coping strategies, and regularly communicating with families in order to foster a fruitful and supportive partnership.

\section{Strengths and limitations}

This study has several strengths. The results support current knowledge regarding challenges faced by family members of cancer patients. The international design gives rise to the possibility of results underpinning the development of international guidelines to foster better nursing support for families.

The study also contributes to the independent validation of the ICE instruments which are grounded in a family nursing conceptual framework as well as years of clinical experience and research (Sveinbjarnardottir et al. 2012a, b). Furthermore, the English versions of the ICE questionnaires were translated and assessed for validity with a Danish population. Both questionnaires were found to be reliable and acceptable to participants, but further validation of the tools is required in different populations. Our study is the first study to administer the ICE questionnaires to both patients and family members in Danish and Australian populations. Our 
study also considered the family as a unit of care as recommended by Family System Nursing model (Bell 2009, Wright \& Leahey 2013).

Limitations to be noted in the study were the different style of data collection between the two countries (on-site and take-home), and the single point of data collection which makes the results a snapshot during the cancer trajectory. Finally, the sample size was relatively modest, with attrition higher in the Australian cohort and fewer family members. However, if family members had been consistent with the numbers of patients the difference may have been even higher. Participants were recruited from only two hospitals which may decrease the generalisability of results.

\section{Relevance to clinical practice}

It is recommended that nurses should assess family functioning during oncology care to better understand perceptions of family functioning from the perspective of both patients and family members. Furthermore, nurses need to adapt information according to the identified needs of family members and prioritise emotional support according to their individual needs. Future research should explore how nursing interventions could better support patients and families as a unit of care. We recommend future longitudinal studies to investigate the patterns of patient and family support needs during the cancer trajectory. Future research could also use mixed methods designs to foster a deeper understanding of participants’ family functioning and perceptions of nursing support.

\section{Conclusion}

Levels of family functioning were found to be comparable between Denmark and Australia. However, family members scored significantly lower than patients on expressive emotions, communication and emotional support. Our results indicate that the emotional support needs of family members were not met. This highlights the need for nurses to consider the family as a unit, 
and for complex needs to be monitored and addressed. Participating families perceived they required more support from nurses during the cancer treatment trajectory. The similarities of issues across countries could enable the development of international guidelines for nursing interventions with families receiving cancer care.

\section{Acknowledgments}

We especially wish to thank the families who participated in the study for their valuable contributions. Furthermore, we would convey our gratitude to our statistician Professor Jørgen T. Lauridsen, University of Southern Denmark for his generous advice regarding statistical analysis and results.

The study was funded by Griffith University/University of Southern Denmark collaborative grant, and is executed on behalf of the Academy of Geriatric Cancer Research (www.agecare.org).

Numbers of words used: 3856 (excluding references) 


\section{Reference List}

Bauer M, Fetherstonhaugh D \& Lewis V (2014): Attitudes towards family-staff relationships in Australian residential aged care settings: development and psychometric evaluation of the 'Family and Staff Relationship Attitude Tool' (FASRAT). Australas J Ageing 33, 170-173.

Bell JM (2009): Family Systems Nursing: re-examined. J Fam Nurs 15, 123-129.

Benzein EG, Hagberg M \& Saveman BI (2008): 'Being appropriately unusual': a challenge for nurses in health-promoting conversations with families. Nurs.Inq. 15, 106-115.

Bloomer MJ, Morphet J, O'Connor M, Lee S \& Griffiths D (2013): Nursing care of the family before and after a death in the ICU-an exploratory pilot study. Aust Crit Care 26, 2328.

Bloomer MJ, O'Connor M, Copnell B \& Endacott R (2015): Nursing care for the families of the dying child/infant in paediatric and neonatal ICU: nurses' emotional talk and sources of discomfort. A mixed methods study. Aust Crit Care 28, 87-92.

Coyne $E$ (2013): The strengths and resources used by families of young women with breast cancer. Australian Journal of Cancer Nursing 14, 10-16.

Coyne E, Grafton E, Reid A \& Marshall A (2016): Understanding family assessment in the Australian context; what are adult oncology nursing practices? Collegian In Press.

Coyne E, Wollin J \& Creedy D (2012): Exploration of the family's role and strengths after a young woman is diagnosed with breast cancer: Views of the women and their families. European Journal of Oncology Nursing 16, 124-130.

Craig L \& Mullan K (2010): Parenthood, Gender and Work-Family Time in the United States, Australia, Italy, France, and Denmark. Journal of Marriage and Family $\mathbf{7 2}$, 1344-1361.

Dieperink KB, Mark K \& Mikkelsen TB (2016): Marital rehabilitation after prostate cancer a matter of intimacy. International journal of Urological Nursing 10, 21-29.

Dieperink KB, Wagner L, Hansen S \& Hansen O (2013): Embracing life after prostate cancer. A male perspective on treatment and rehabilitation. Eur J Cancer Care 22, 549-558.

Friedman M, Bowden V \& E J (2003) Family Nursing Research, Theory, and Practice, 5 edn. Printice Hall, New Jersey.

Halldórsdóttir B \& Svavarsdóttir E (2012): Purposeful Therapeutic Conversations: Are They Effective for Families of Individuals with COPD: A Quasi-Experimental Study. . Nordic Journal of Nursing Research, 48-51.

Harris JN, Hay J, Kuniyuki A, Asgari MM, Press N \& Bowen DJ (2010): Using a family systems approach to investigate cancer risk communication within melanoma families. Psychooncology 19, 1102-1111.

Kamban SW \& Svavarsdottir EK (2013): Does a therapeutic conversation intervention in an acute paediatric setting make a difference for families of children with bronchiolitis caused by respiratory syncytial virus (RSV)? J Clin Nurs 22, 27232733.

Kean S \& Mitchell M (2014): How do intensive care nurses perceive families in intensive care? Insights from the United Kingdom and Australia. J Clin Nurs 23, 663-672.

Kim Y, Kashy DA, Spillers RL \& Evans TV (2010): Needs assessment of family caregivers of cancer survivors: three cohorts comparison. Psychooncology 19, 573-582.

King DW \& Lashley R (2000): A quantifiable alternative to double data entry. Control Clin.Trials 21, 94-102. 
Munns A \& Shields L (2013): Indigenous families' use of a tertiary children's hospital in Australia. Nurs Child Young People 25, 16-23.

Northouse L, Williams AL, Given B \& McCorkle R (2012): Psychosocial care for family caregivers of patients with cancer. J Clin Oncol 30, 1227-1234.

Northouse LL, Katapodi MC, Song L, Zhang L \& Mood DW (2010): Interventions with family caregivers of cancer patients: meta-analysis of randomized trials. Cancer $\mathrm{J}$ Clin 60, 317-339.

Osoba D, Rodrigues G, Myles J, Zee B \& Pater J (1998): Interpreting the significance of changes in health-related quality-of-life scores. J Clin Oncol 16, 139-144.

Ostergaard B \& Wagner L (2014): The development of family nursing in Denmark: current status and future perspectives. J Fam Nurs 20, 487-500.

Pritchett R, Kemp J, Wilson P, Minnis H, Bryce G \& Gillberg C (2011): Quick, simple measures of family relationships for use in clinical practice and research. $A$ systematic review. Fam Pract 28, 172-187.

Rademakers J, Delnoij D, Nijman J \& de Boer D (2012): Educational inequalities in patientcentred care: patients' preferences and experiences. BMC Health Serv Res 12, 261.

Rillotta F, Kirby N, Shearer J \& Nettelbeck T (2012): Family quality of life of Australian families with a member with an intellectual/developmental disability. $J$ Intellect Disabil Res 56, 71-86.

Ross L, Petersen MA, Johnsen AT, Lundstrom LH, Lund L \& Groenvold M (2012): Using mixed methods to assess how cancer patients' needs in relation to their relatives are met in the Danish health care system: a report from the population-based study "The Cancer Patient's World". Support Care Cancer 20, 3211-3220.

Schneider JK \& Deenan A (2004): Reducing quantitative data errors: tips for clinical researchers. Appl Nurs Res 17, 125-129.

Sveinbjarnardottir EK, Svavarsdottir EK \& Hrafnkelsson B (2012a): Psychometric development of the Iceland-Expressive Family Functioning Questionnaire (ICEEFFQ). J Fam Nurs 18, 353-377.

Sveinbjarnardottir EK, Svavarsdottir EK \& Hrafnkelsson B (2012b): Psychometric development of the Iceland-Family Perceived Support Questionnaire (ICE-FPSQ). J Fam Nurs 18, 328-352.

Sveinbjarnardottir EK, Svavarsdottir EK \& Wright LM (2013): What are the benefits of a short therapeutic conversation intervention with acute psychiatric patients and their families? A controlled before and after study. Int J Nurs Stud 50, 593-602.

Turner J, Clavarino A, Yates P, Hargraves M, Connors V \& Hausmann S (2007): Oncology nurses' perceptions of their supportive care for parents with advanced cancer: challenges and educational needs. Psychooncology 16, 149-157.

Walsh F (2006) Strengthening Family Resilience, 2 edn. The Guilford Press, New York.

Winek JL (2010) Systemic family therapy: From theory to practice. Sage, Los Angeles.

Wong P, Liamputtong P, Koch S \& Rawson H (2015): Families' experiences of their interactions with staff in an Australian intensive care unit (ICU): a qualitative study. Intensive Crit Care Nurs 31, 51-63.

World Medical Association (2008) World Medical Association declaration of Helsinki http://www.wma.net/en/30publications/10policies/b3/index.html.

Wright LM \& Leahey M (1990): Trends in nursing of families. J Adv Nurs 15, 148-154.

Wright LM \& Leahey M (2013) Nurses and families. A guide to family assessment and intervention, 6 edn. F. A. Davis Company, Philadelphia. 
Yates P (1999): Family coping: issues and challenges for cancer nursing. Cancer Nurs 22, 63-71. 